\title{
A EVOLUÇÃO DO SISTEMA INTERAMERICANO DE PROTEÇÃO DOS DIREITOS HUMANOS
}

\author{
THE EVOLUTION OF THE INTERAMERICAN SYSTEM OF HUMAN RIGHTS PROTECTION
}

\section{Rogerio Taiar}

\begin{abstract}
Resumo:
Esta matéria consiste num breve estudo sobre o sistema interamericano de proteção dos direitos humanos através da análise da sua evolução histórica, estrutura normativa e objetivos no que diz respeito às suas funções consultiva e judicial.

Palavras-chave: Sistema interamericano. Direitos humanos. Estrutura normativa.
\end{abstract}

\begin{abstract}
:
This article is a brief study on the Interamerican System of Human Rights protection through the analysis of its historical evolution, legal structure and objectives regarding its consulting and judicial functions.
\end{abstract}

Keywords: Interamerican system. Human rights. Legal structure.

\section{Introdução}

$\mathrm{Na}$ atualidade temos observado graves problemas vinculados à proteção dos direitos humanos. Tem-se assistido a verdadeiras tragédias onde não faltam, efetivamente, agressões à dignidade da pessoa humana sob as mais variadas formas de violação aos direitos humanos, desde guerras deflagradas sob o pálio de legítimo exercício de defesa à injusta agressão, a condutas omissivas, que igualmente conduzem a situações desastrosas, até mesmo catastróficas com perecimento de milhares de vidas.

A confiança na impunidade tem conduzido a vida no planeta a uma situação aflitiva de instabilidade e de insegurança, tudo em detrimento de um espaço propício para o desenvolvimento da vida em sua plenitude.

Nos últimos tempos, os direitos humanos vêm adquirindo um lugar cada vez mais considerável na consciência política e jurídica contemporânea. ${ }^{1}$ Por outro lado, a presença das garantias em instrumentos internacionais de proteção dos direitos humanos, sobretudo na Convenção Interamericana de Direitos Humanos, cuja análise será objeto do presente trabalho, possibilita a responsabilização do Estado Nacional pelo desrespeito às mesmas. Com isso, observamos um valioso instrumento que possibilita ao indivíduo

\footnotetext{
Doutorando em Direitos Humanos pela Faculdade de Direito da Universidade de São Paulo. Pós-Graduado em Direito Penal pela Universidad de Salamanca (Espanha).

1 TRINDADE, Antonio Augusto Cançado. Ao Legado de Viena. A incorporação das normas internacionais de proteção dos Direitos Humanos no Direito brasileiro. In: CONFERÊNCIA MUNDIAL DE DIREITOS HUMANOS, II, 1993. 1996. p. 19.
} 
cobrar atitudes ou denunciar atos lesivos por parte do Estado frente a esses organismos internacionais.

A “nova ordem mundial”, os processos de integração econômica, os acordos mundiais de comércio e os pactos de não-ploriferação de armas nucleares são importantes passos da evolução da comunidade internacional, no sentido de cada vez mais reunir e irmanar os países em torno de uma finalidade comum. Mas, ao lado de todo este esforço, existe uma verdadeira mancha negra que paira ainda sobre muitos no mundo: a guerra, a fome e a destruição. Assim sendo, é necessário que haja um esforço em compreender este tema, devido à necessidade real de sua aplicação prática como a realidade dos fatos nos demonstra.

O Sistema Interamericano de Proteção dos Direitos Humanos apresenta como principal função a promoção da observância e da defesa dos direitos humanos.

\section{A proteção internacional dos Direitos Humanos}

\subsection{Evolução Histórica}

A noção de "direitos humanos" surgiu no Direito interno tendo adquirido, entretanto, grande importância no plano internacional. As fontes nacionais desta forma precedem as fontes de Direito Internacional. É do fim do século XVIII que datam as Declarações Americana (1776) e Francesa (1789). Nesta ocasião, os direitos reconhecidos consagraram, essencialmente, as liberdades individuais sendo que os direitos sociais só foram reconhecidos mais tarde.

O movimento internacional de proteção dos direitos humanos se desenvolveu por sua vez em sentido inverso ao dos direitos nacionais, ou seja, observa-se que a consagração dos chamados direitos sociais se deu em momento anterior a dos direitos individuais. Visando a proteção dos direitos econômicos e sociais, no ano de 1919 foi criada a Organização Internacional do Trabalho e somente após a Segunda Guerra Mundial é que os direitos civis e políticos e os direitos do homem no seu todo foram consagrados no plano internacional.

Contudo, a verdadeira consolidação do Direito Internacional dos Direitos Humanos surge em meados do século XX, em decorrência da Segunda Guerra Mundial, nascendo a certeza de que a proteção dos direitos humanos não deveria se reduzir ao âmbito estatal (nacional), revelando-se como um legítimo interesse internacional. Assim sendo, a violação dos direitos humanos não poderia mais ser vista como uma questão doméstica do Estado, mas sim um problema de relevância internacional.

Desta forma, a necessidade de uma proteção mais eficaz dos direitos humanos, impulsionou o processo de internacionalização desses direitos, culminando com a criação 
da sistemática normativa de proteção internacional, possibilitando a responsabilização do Estado no domínio internacional, quando as instituições nacionais se mostram falhas ou omissas na tarefa de proteção dos direitos humanos.

Assim sendo, o Direito Internacional que sempre esteve tradicionalmente enfocado como ramo do Direito que regula as relações entre Estados, uma vez que suas regras não deveriam, por esse motivo, ingerir na esfera interna dos países, para regular as relações entre estes e seus cidadãos, com a regulamentação dos direitos humanos no âmbito internacional, fez com que o Estado deixasse de ser "sacrossanto", deixando de ser um fim em si mesmo.

A existência do Estado passou a ser desafiada: agora, o Estado tinha uma razão de ser, e poderia perder a sua legitimidade se falhasse em sua missão.

Todo Estado deve cumprir sua obrigação de proteger seus cidadãos, sua vida e sua integridade física. No momento em que se transforma em um aparato de repressão e terror, perseguindo algumas parcelas de seu povo, a estes grupos não cabe mais a obrigação de permanecer leais a este Estado.

A criação de tratados, institutos internacionais e como conseqüência o aparecimento de obrigações internacionais voltadas à salvaguarda dos direitos do ser humano rompe, assim, com a noção de soberania nacional absoluta, na medida em que admitem intervenções no plano nacional, em prol da proteção dos direitos humanos.

Aos poucos surge a idéia de que o indivíduo não é apenas um objeto, mas também um sujeito de Direito Internacional, começando a se consolidar a capacidade processual internacional deste.

O moderno Direito Internacional dos Direitos Humanos é um fenômeno do pós-guerra, ${ }^{2}$ no momento em que os seres humanos se tornam supérfluos e descartáveis, em que vige a lógica da destruição, em que cruelmente se abole o valor da pessoa humana, emerge a necessidade de reconstrução dos direitos humanos.

O processo de internacionalização dos direitos humanos, pressupondo uma delimitação da soberania estatal, passa, assim, a ser uma importante resposta na busca dessa reconstrução.

A criação das Nações Unidas demarca o surgimento de uma nova ordem internacional e consolida o movimento de internacionalização dos direitos humanos, mas somente três anos após o advento da Carta das Nações Unidas, a Declaração Universal dos Direitos Humanos, de 1948, veio a definir com precisão o elenco dos "direitos humanos e liberdades fundamentais".

2 BUERGENTHAL, Thomas. International Human Rights. Minessota: West Publishing, 1988, obra citada por PIOVESAN, Flávia. Direitos Humanos e o Direito Constitucional Internacional. Max Limonad: São Paulo, 1997. p. 140. 
A Declaração consolida a afirmação de uma ética universal, ${ }^{3}$ consagrando um consenso sobre valores a serem seguidos pelos Estados. A Declaração consagra tanto direitos civis e políticos (arts. $3^{\circ}$ a 21) quanto direitos sociais (arts. 22 a 28), demarcando assim a teoria contemporânea dos direitos humanos.

\subsection{A estrutura normativa}

Auniversalização dos direitos humanos fez com que os Estados concordassem em se submeterem ao controle da comunidade internacional.

A Carta da ONU, de 1945, já estabelece em seu art. 55 que os Estadospartes deveriam promover a proteção dos direitos humanos e das liberdades fundamentais, sendo que, em 1948, a Declaração Universal vem a definir e fixar o elenco dos direitos e liberdades fundamentais a serem garantidos.

Em 1966, são elaborados dois Tratados internacionais distintos: o Pacto Internacional dos Direitos Civis e Políticos e o Pacto Internacional dos Direitos Econômicos, Sociais e Culturais, os quais transformaram os dispositivos da Declaração Universal em previsões juridicamente vinculantes e obrigatórias.

A partir da elaboração desses dois pactos, formou-se a Carta Internacional de Direitos Humanos. Esse sistema global de proteção dos Direitos Humanos passou a ser ampliado através do advento de diversos tratados multilaterais: Convenção Internacional contra o Genocídio, Convenção Internacional contra a Tortura, Convenção Internacional sobre a eliminação de todas as formas de discriminação racial, dentre outras.

Esses tratados internacionais de direitos humanos buscam garantir o exercício de direitos e liberdades fundamentais aos indivíduos. Outrossim, o Direito Internacional dos Direitos Humanos não pretende substituir o sistema nacional, mas sim, enquanto um direito paralelo e suplementar a este, permitir que sejam superadas suas omissões e deficiências. ${ }^{4}$

\subsection{Os sistemas regionais}

Ao lado do sistema global de proteção dos direitos humanos, surge o sistema regional de proteção que busca internacionalizar os direitos humanos no plano regional, particularmente na Europa, América e África.

\footnotetext{
3 ANTUNES, Eduardo Muylaert. Natureza Jurídica da Declaração Universal dos Direitos Humanos. Revista dos Tribunais, São Paulo, n. 446, p. 25-36, dez. 1972.

4 PIOVESAN, Flávia. Direitos Humanos e o Direito Constitucional Internacional. São Paulo: Max Limonad, 1997.
} 
Cada sistema regional apresenta um aparato jurídico próprio, importando para o presente estudo a análise da Convenção Européia de Direitos Humanos, de 1950, e da Convenção Americana de Direitos Humanos, de 1969, que reconhecem e asseguram um catálogo de direitos, cabendo aos Estados-partes a obrigação de respeitar e assegurar o livre e pleno exercício desses direitos, adotando medidas legislativas e de outra natureza que sejam necessárias para conferir a efetividade aos direitos enunciados.

\subsubsection{Quadro cronológico:}

Declaração Universal dos Direitos do Homem (1948)

Convenção Européia dos Direitos do Homem (1950)

Convenção Americana de Direitos Humanos - Pacto de San José da Costa Rica (1969)

2. O sistema interamericano de proteção dos Direitos Humanos

2.1. Evolução histórica

O Sistema Interamericano de Proteção dos Direitos Humanos foi desenvolvido no âmbito da Organização dos Estados Americanos (OEA), enquanto um sistema regional de proteção dos direitos humanos, coexistindo, por sua vez, com o sistema universal de direitos humanos da ONU. ${ }^{5}$

No ano de 1948, durante a Nona Conferência Interamericana de Estados Americanos, foi adotada pelos Estados Americanos a chamada "Declaração Americana dos Direitos e Deveres do Homem" e, posteriormente, no ano de 1959, durante a Quinta Reunião de Consulta de Ministros de Relações Exteriores dos países-membros da OEA, foi aprovada a Resolução que criou a Comissão Interamericana de Direitos Humanos. Ocorrendo, contudo, no ano de 1965, durante a Segunda Conferência Interamericana, uma modificação dos seus estatutos, tendo sido ampliada a sua atuação.

No ano de 1970, ocorreram novas modificações nos estatutos da Comissão Interamericana de Direitos Humanos, a qual passou de entidade autônoma a um dos principais órgãos da OEA, sendo que no ano anterior, ou seja, em 1969, os Estados Americanos adotaram em São José, Costa Rica, a Convenção Americana sobre Direitos Humanos, a qual entrou em vigor no ano de 1978. Esta Convenção, por sua vez, estipulou a criação da Corte Interamericana de Direitos Humanos.

5 HANASHIRO, Olaya Silvia Machado Portella. O sistema interamericano de proteção aos Direitos Humanos. São Paulo: Edusp, 2001. 
O Brasil ratificou a Convenção Americana em 1992 e aceitou, em 1998, a competência contenciosa da Corte Interamericana como órgão encarregado de questões pendentes de solução judicial.

\subsection{Os órgãos do Sistema Interamericano de Proteção dos Direitos Humanos}

O Sistema Interamericano de Proteção dos Direitos Humanos tem por base dois órgãos principais, sendo eles: a) A Comissão Interamericana de Direitos Humanos e; b) Corte Interamericana de Direitos Humanos.

Dentre as principais funções do Sistema Interamericano de Proteção dos Direitos Humanos encontra-se a supervisão do cumprimento, por parte dos Estados, dos tratados interamericanos de direitos humanos, tendo competência para receber denúncias individuais de violação dos referidos tratados.

A Comissão Interamericana de Direitos Humanos, em conformidade com o disposto pelo art. $1^{\circ}$ do seu estatuto é um órgão da OEA criado para promover a observância e a defesa dos direitos humanos, bem como servir como órgão consultivo da OEA, nesta matéria.

A Corte Interamericana de Direitos Humanos consiste em um tribunal internacional criado pela Convenção Americana sobre Direitos Humanos com sede em São José, Costa Rica, tendo uma função consultiva e outra contenciosa.

A função consultiva consiste na faculdade de emissão de pareceres consultivos sobre a interpretação da Convenção Americana e de outros tratados relativos à proteção dos direitos humanos, bem como no que diz respeito à compatibilidade da legislação interna de um Estado com tais instrumentos internacionais; já a função contenciosa, por sua vez, consiste no conhecimento de casos individuais nos quais se alega a violação de direitos humanos por parte de um Estado-Parte.

A função judicial vincula os Estados-partes, sendo as sentenças da Corte Interamericana obrigatórias, tendo por finalidade garantir à vítima o gozo de seu direito ou liberdade violados, a reparação de conseqüências ou o pagamento de indenização, bem como promover a adoção de ações corretivas, por parte dos Estados, para as deficiências dos sistemas judiciários nacionais.

Outrossim, é essencial para a própria vitalidade do Sistema Interamericano de proteção dos direitos humanos o cumprimento, por parte dos Estados-partes, das sentenças da Corte, bem como das recomendações da Comissão Interamericana de Direitos Humanos.

Contudo, tendo em vista o caráter subsidiário que o sistema interamericano de proteção dos direitos humanos possui em relação à proteção a ser proporcionada pelos Estados, conforme o art. 46/1 da Convenção, para que uma denúncia seja aceita, há a 
necessidade de terem sido interpostos e esgotados os recursos da jurisdição nacional, ou seja, da jurisdição interna do Estado-parte em questão.

2.3. Demais instrumentos de proteção dos Direitos Humanos

São diversos os instrumentos relativos à proteção dos direitos humanos adotados pelos Estados Americanos, dentre eles pode-se destacar a Convenção Interamericana para Prevenir e Sancionar a Tortura, que entrou em vigor no ano 1987. No ano de 1988 foi adotado o chamado Protocolo de Salvador, protocolo adicional à Convenção Americana, relativo aos Direitos Econômicos, Sociais e Culturais, ${ }^{6}$ entrando em vigor no ano de 1999, tendo sido ratificado pelo Brasil no ano de 1996.

No ano de 1990, outro protocolo adicional à Convenção Americana fora adotado, denominado Protocolo à Convenção Americana sobre Direitos Humanos Relativo à Abolição da Pena de Morte, entrando em vigor no ano de 1991 e ratificado pelo Brasil no ano de 1996. Além desses, no ano de 1994, foram aprovados dois tratados relativos Direitos Humanos, sendo eles a Convenção Interamericana sobre o Desaparecimento Forçado de Pessoas e a Convenção Interamericana para Prevenir, Sancionar e Erradicar a Violência contra a Mulher.

3. Conclusão

Nos últimos anos observamos um movimento de reconstrução dos direitos humanos como paradigma e referencial ético a orientar a ordem internacional contemporânea. O Sistema Interamericano de Proteção dos Direitos Humanos vem evoluindo com o passar dos anos através da criação de diferentes órgãos e instrumentos internacionais de direitos humanos, representando um importante instrumento de promoção e proteção dos direitos humanos.

Por outro lado, muito ainda deve ser feito para que o Sistema Interamericano de Proteção dos Direitos Humanos se torne mais efetivo, sobretudo no que diz respeito ao conhecimento limitado acerca do mesmo freqüente na maioria dos países do hemisfério americano.

Entretanto, apesar de tudo, o Sistema Interamericano de Proteção dos Direitos Humanos continua a realizar o papel ao qual se propõe, isto é, obter justiça em relação às violações de direitos humanos, alargando com isso as do Estado, incorporando objetivos vinculantes das instâncias de regulação jurídica. Outrossim, a política deixa de

${ }^{6}$ GROS ESPIELL, Hector. Los derechos económicos, sociales y culturales en el sistema interamericano. San José: Libro Libre, 1986. 
ser concebida como um domínio juridicamente livre e desvinculado, passando a sofrer limites e imposições em virtude da necessidade de observância e garantia de direitos.

A agenda de direitos humanos deve ser, assim, incorporado na atuação dos

Estados sendo com isso consagrado o princípio da responsabilidade internacional dos Estados, no que se refere ao respeito aos direitos humanos.

São Paulo, dezembro de 2008.

Referências

ACCIOLY, Hildebrando; SILVA, Geraldo Eulálio do Nascimento e. Manual de direito internacional público. 12. ed. São Paulo: Saraiva, 1996.

ANTUNES, Eduardo Muylaert. NaturezajJurídica da Declaração Universal dos Direitos Humanos. Revista dos Tribunais, São Paulo, n. 446, p. 25-36, dez. 1972.

GROS ESPIELL, Hector. Los derechos económicos, sociales y culturales en el sistema interamericano. San José: Libro Libre, 1986.

HANASHIRO, Olaya Silvia Machado Portella. O sistema interamericano de proteção aos Direitos Humanos. São Paulo: Edusp, 2001.

MELLO, Celso Duvivier de Albuquerque. Curso de direito internacional público. Rio de Janeiro: Livraria Editora Renovar, 1997.

PIOVESAN, Flávia. Direitos Humanos e o Direito Constitucional Internacional. São Paulo: Max Limonad, 1997.

REZEK, José Francisco. Direito dos tratados. Rio de Janeiro, Forense, 1984.

TRINDADE, Antonio Augusto Cançado. Ao Legado de Viena. A incorporação das normas internacionais de proteção dos direitos humanos no direito brasileiro. In: CONFERÊNCIA MUNDIAL DE DIREITOS HUMANOS, II. 1993, San Jose, Costa Rica. 1996. 